\title{
The role of transforming growth factor-beta in Marfan syndrome
}

\author{
Kálmán Benke ${ }^{1,2}$, Bence Ágg ${ }^{1,2}$, Bálint Szilveszter ${ }^{1}$, Ferenc Tarr ${ }^{1}$, Zsolt B. Nagy ${ }^{3}$, \\ Miklós Pólos ${ }^{1}$, László Daróczi ${ }^{1}$, Béla Merkely ${ }^{1}$, Zoltán Szabolcs ${ }^{1,2}$ \\ ${ }^{1}$ Department of Cardiology and Cardiovascular Surgery, Semmelweis University, Budapest, Hungary \\ ${ }^{2}$ Hungarian Marfan Foundation, Budapest, Hungary \\ ${ }^{3}$ Genetics for Health Association, Budapest, Hungary
}

\begin{abstract}
The starting point, in Marfan syndrome (MFS) appears to be the mutation of fibrillin-1 gene whose deconstructed protein product cannot bind transforming growth factor beta (TGF- $\beta$ ), leading to an increased TGF- $\beta$ tissue level. The aim of this review is to review the already known features of the cellular signal transduction downstream to TGF- $\beta$ and its impact on the tissue homeostasis of microfibrils, and elastic fibers. We also investigate current data on the extracellular regulation of TGF- $\beta$ level including mechanotransduction and the feedback cycles of integrin-dependent and independent activation of the latent TGF- $\beta$ complex. Together these factors, by the destruction of the connective tissue fibers, may play an important role in the development of the diverse cardiac and extracardiac manifestations of MFS and many of them could be a target of conservative treatment. We present currently investigated drugs for the treatment of the syndrome, and explore possible avenues of research into pathogenesis of MFS in order to improve understanding of the disease. (Cardiol J 2013; 20, 3: 227-234)
\end{abstract}

Key words: Marfan syndrome, aortic aneurysm, transforming growth factor-beta (TGF- $\beta$ ), matrix-metalloprotease (MMP)

\section{Introduction}

Marfan syndrome (MFS) is an inherited autosomal-dominant disease of the connective tissue [1]. In most cases, mutation of fibrillin 1 gene (FBN1) can be identified [2]. This gene produces fibrillin 1 protein, which is the main constituent of microfibrils in the extracellular matrix. These fibres play an important role in incorporating elastin into elastic fibres [3]. FBN1 gene is located at a chromosomal position of $15 \mathrm{q} 21.1$, and shows more than 1000 variation in mutation associated with different syndromes (MFS, acromicric dysplasia, geleophysic dysplasia 2, MASS syndrome, Shprintzen-Goldberg syndrome, Stiff skin syn- drome, Weill-Marchesani syndrome 2) [1]. These mutations lead to impaired protein synthesis and secretion, or defective incorporation into the connective tissue [2]. FBN1 mutation thus results in disintegration and fragmentation of connective tissue fibres leading to tissue fragility and elongation. Some syndrome manifestations can be directly ascribed to these structural abnormalities [2]. For genotype-phenotype analysis, mutations were divided into three groups: missense mutation, nonsense mutation and frameshift mutation [4]. Knowledge of the type and location of an FBN1 mutation may be useful in providing further clinical correlation regarding phenotypic progression and appropriate medical management [5].

Address for correspondence: Kálmán Benke, Department of Cardiology and Cardiovascular Surgery, Semmelweis University, Varosmajor utca 68, 1122 Budapest, Hungary, e-mail: kalman.benke@gmail.com 
In MFS, the fragility of the connective tissue weakens the ability of the aortic wall to withstand intraluminal pressure and aneurysm formation may result [6]. The extravascular manifestations such as joint hyperflexibility and ocular lens ectopy are probably also related to the connective tissue disorder [6]. It is probable that MFS induces endothelial dysfunction as well: endothelial cell adherence unavoidably requires microfibrils with intact structure and fibrillin 1 protein [7], and structural disruption in this context leads to defective adhesion and subsequent endothelial abnormalities in the arteries [7]. Though fibrillin 1 protein defect plays a role in some of the extracardiac manifestations, the typical musculo-skeletal appearances may be caused by other molecular pathological mechanisms, including elevated TGF- $\beta$ levels.

\section{Marfan syndrome from a novel point of view}

The first step in the pathogenesis of MFS is the production of the altered protein product of the mutated FBN1 gene which results in the disruption of microfibrils and elastic fibers [5]. Therefore to understand the exact pathological mechanism, and to find salvage mechanisms for defective fibrillin-1, it is crucial to be familiar with the homeostasis of microfibrils and elastic components, a subject which has received relatively little attention despite its clinical and scientific importance.

The link between fibrillin-1 homeostasis and a new molecular family, called ADAMTS (A Disintegrin And Metalloproteinase ThromboSpondin motifs) has been recently studied. Mutations in ADAMTS10 and fibrillin-1 genes cause Weill-Marchesani syndrome [8]. One feature, lens ectopy is common to both syndromes, while several features of Weil-Marchesani syndrome are the opposite of those that typical to MFS including brachydactyly, small stature and stiff joints [9]. Dysfunction of ADAMTS leading to dislocated lens has been described in another study [10]. Apart from ADAMTS 10 , isolated mutation of ADAMTS4 also causes lens ectopy [10]. ADAMTS 10 binds to fibrillin-1 with high affinity and appears to be indispensable to microfibril biogenesis [11]. Others demonstrated that proper structure and connection of the two proteins is necessary for the correct construction of the microfibrillar system [12]. The ADAMTSL6 $\beta$ protein was reported to play an essential role in connective tissue structure and regeneration [13]. Expression of ADAMTSL6 $\beta$ improved microfibril impairment following periodontal ligament injury in a Marfan mouse model, and it also stimulates microfibril regeneration [13]. Moreover, the level of TGF- $\beta$ released in high concentration is reduced in the periodontal ligaments right after ADAMTSL6 $\beta$ administration [13]. Present data may prove a fundamental role of ADAMTSL6 $\beta$ in restructuring fibrillin-1 associated microfibrils [13]. These results suggest that a novel therapeutic strategy can be designed for the treatment of MFS based upon the knowledge of ADAMTS 10- and ADAMTSL6 $\beta$-mediated microfibril biogenesis.

\section{The role of TGF- $\beta$ in the manifestations of Marfan syndrome}

The failure of physiological processes like remodeling and salvage of microfibrils and the associated rise in the plasma level of the active TGF- $\beta$ lead to the well-known manifestations of the syndrome.

Chaudhry et al. [14] stated in 2007, that mutation of fibrillin 1 alters intercellular communication, and significantly increases TGF- $\beta$ protein level in the extracellular space. TGF- $\beta$ is a paracrine regulatory molecule of several processes, including embryonic development, cell growth and apoptosis induction [15]. Among others, it also enhances collagen production and extracellular matrix (ECM) remodeling [16]. Although its effect is concentration-dependent, it is also affected by other factors beyond mere quantity in the tissue. TGF- $\beta$ is produced in dimer form in the cells and is being bound with latency-associated protein (LAP) to form small latent complex (SLC) [16]. This secreted SLC is bound extracellularly to latent TGF- $\beta$ binding protein (LTBP) to form large latent complex (LLC) [16]. LLC is then attached to microfibrils of fibrillin-1 by LTBP. The "latency" part in the nomenclature of these molecules reflects their functional role in maintaining the inactive form of TGF- $\beta$ [16].

TGF- $\beta$ can only be activated by a series of organized and complex regulatory mechanisms, the appropriate function of which play a key role in human development. In MFS, fibrillin 1 mutation occurs, and LLC becomes unable to attach to microfibrils [16]. Latent form is not generated, resulting in elevated serum TGF- $\beta$ level [16]. TGF- $\beta$ joins to its dimer receptor forming a complex which induces the phosphorylation cascade [16].

Another mutation in the TGF- $\beta$ binding receptor 2 (TGFBR2) gene causes failure in signaling pathways and results in the development of a Marfan-like syndrome called Marfan type II [16]. 
So far the number of identified cases is small, but they also exhibit skeletal and cardiovascular manifestations similar to those in patients with FBN1 mutations [17]. The phenotypic differences between the mutations that can cause the variants of MFS (FBN1, TGFBR1, TGFBR2, TGFBR3) are difficult to distinguish, and there is a large overlap in the clinical presentation of these mutations [18]. Recently, mutations in TGFBR3 were also linked to MFS [18]. According to Attias et al. [19] the clinical outcomes between classical and type II MFS appear similar and the prognosis depends on the strength of the expression of the genetic disease and the treatment rather than the presence of TGFBR2 mutation [19].

\section{TGF- $\beta$ activation pathways}

As a growing body of evidence supports the view that elevated TGF- $\beta$ levels may play a central role in the development of the manifestations specific to MFS, all factors that can modulate active TGF- $\beta$ levels should be studied in order to understand the diversity and variable expressivity observed in the phenotypes of the patients with the syndrome. One such factor is the activation of the latent TGF- $\beta$ complex. Polymorphisms in gene-encoding molecules that participate in the activation process may be responsible for the variable expressivity.

Among the known activating pathways proteases, integrins, $\mathrm{pH}$ alteration and free oxygen radicals are all capable triggers for TGF- $\beta$ activation [20-23]. TGF- $\beta$ activation may occur by integrinindependent, or integrin-related pathways. Possible mediators of integrin-independent TGF- $\beta$ activation are matrix-metalloproteases (MMPs) playing a role in tissue remodeling via proteolysis of the extracellular matrix [24]. TGF- $\beta$ release and activation by MMPs are well-recognized phenomena. TGF- $\beta$ activation is also influenced by $\mathrm{pH}$, since latency-associated protein (LAP) disintegrates in an acidic environment [20]. Although it is known from in vitro experiments that in extreme $\mathrm{pH}$ environments ( $\mathrm{pH} 1,5$ or 12 ) TGF- $\beta$ activation significantly increases, further research is needed to clarify the physiological role of this effect [20].

Another pathway of integrin-independent activation is the effect of reactive oxygen species (ROS) [21]. Fast activation of TGF- $\beta$ happens by radiation, due to alteration of LAP and the molecule interaction [21]. Trombospondin-1 (TSP-1) is a cell glycoprotein, and its concentration may increase in conditions such as inflammation leading to activation of dormant TGF- $\beta$ [22].
Presently, there are two accepted modalities, which explain TGF- $\beta 1$ activation by integrins containing $\beta \mathrm{V}$. According to the first one, conformation alteration takes place in the inactive TGF- $\beta$ complex induced by integrins resulting in an active form of TGF- $\beta$ [23]. $\alpha \mathrm{V} \beta 6$ integrin is known to be the first TGF- $\beta$ activator: when bound to the LAP arginine-glycine-aspartic acid (RGD) sequence, an alteration in conformation occurs, while the adhesion-mediated effects of intercellular influences brings about TGF- $\beta$ activation via a biochemical process [23]. This process happens in case of the high rigidity of the microfibrillar system, which is not capable of withstanding the shear stress, generated by integrin bonding. In these instances, integrin bound to RGD sequences excludes TGF- $\beta$ from its complex [23, 25].

The other modality is the mechanism of protease-dependent activation of integrin. TGF- $\beta$ can be activated by MMP- 2 and MMP- 9 by proteolytic degradation of the inactive (latent) TGF- $\beta$ complex [26]. $\alpha \mathrm{V}$ may enhance this process as it tightens the interaction of the molecules. Integrin $\alpha \mathrm{V} \beta 6$ and $\alpha \mathrm{V} \beta 3$ are simultaneously bound to latent TGF- $\beta$ complex and to MMPs - as catalysts to speed up complex degradation [26]. In conclusion, from the perspective of MFS the mechanosensor function of TGF- $\beta$ seems to be important. Elasticity of the microfibrillar system affects the extent of TGF- $\beta$ release from the latent complex. When connective tissue is inelastic, the elevated active TGF- $\beta$ level, by increasing the expression of certain proteases including MMPs, induces the remodelling of the ECM [24] (see below). This negative feedback cycle in the mechanosignalling process eventually allows the fine tuning of the connective tissue elasticity [23]. The aforementioned activating modalities, by altering the tissue concentration of the active form of TGF- $\beta$, may affect the dynamic equilibrium maintained by the mechanotransduction feedback and thus modify the severity of the manifestations in MFS (Fig. 1) [23]. Therefore, better understanding of this function together with the clarification of the possible role of gene polymorphisms, may help to explain the important phenotypical variations in Marfan patients. These modalities offer a potential research opportunity for the development of drugs to modify the course of MFS by diminishing TGF- $\beta$ tissue levels.

\section{TGF- $\beta$ signal transduction pathways in Marfan syndrome}

There are two distinct ways of intracellular signaling, through which elevated TGF- $\beta$ level 


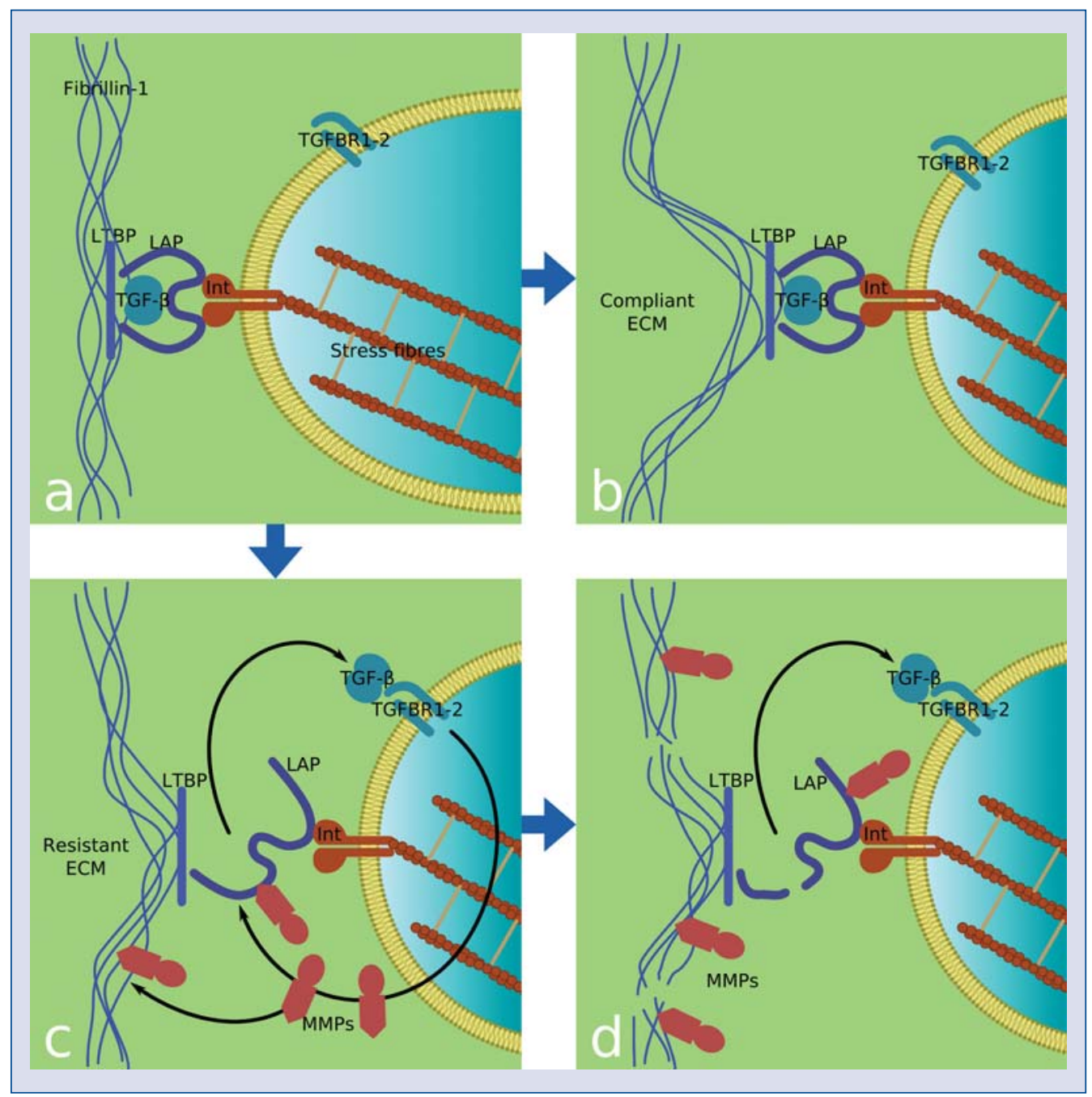

Figure 1. In this picture mechanotransduction mediated by the integrin dependent activation of latent transforming growth factor-beta (TGF- $\beta$ ) is illustrated. In part A no forces exerted on the large latent complex (LLC) composed of the inactive form of TGF- $\beta$, latency associated protein (LAP), and latent TGF- $\beta$ binding protein (LTBP). In this steady state no TGF- $\beta$ activation happens by mechanical forces. In part $\mathbf{B}$ and $\mathbf{C}$ mechanical forces arising from actin stress fibre mediated cell traction or other sources (e.g. aortic wall tension) are exerted on the LLC with through integrin molecules (Int). However in part B compliant extracellular matrix (ECM) adapts to this effect and no further TGF- $\beta$ activation happens. Contrary in part $\mathbf{C}$ because of the resistant ECM no such adaptation happens causing the conformation change of the lap molecule and as a consequence the integrin mediated liberation of TGF- $\beta$. Active TGF- $\beta$ through its receptor (TGFBR1-2) induces the expression of matrix metalloproteinases, including gelatinases (MMP-2 and MMP-9) - which then can cleave the microfibrillar network, other fibre components in the ECM, and also LAP protein. The latter increases the activation of the latent TGF- $\beta$, thus a positive feedback cycle occurs. In part $\mathbf{D}$ cleaved ECM components and cleaved LAP are depicted as a result of the negative feedback regulation of the ECM compliance by integrin and TGF- $\beta$ mediated mechanosignalling.

can exert its detrimental effects: the so-called canonical and non-canonical signal transduction $[27,28]$. The former pathway is mediated by the Smad proteins [27]. In MFS Smad2 protein plays an exclusive role [27]. By forming a complex with Smad4, CBP and P300 Smad2 regulates transcription and induces MMP production (Fig. 2).
Gomez et al. concluded in 2011 [27] that the signalling pathway of TGF- $\beta /$ Smad2 plays a crucial role in the development of thoracic aortic aneurysms of different etiology. Increased expression of Smad2 may cause histological aortic wall changes. Epigenetic factors influence the expression levels of Smad2. Chromatin immunoprecipitation showed 


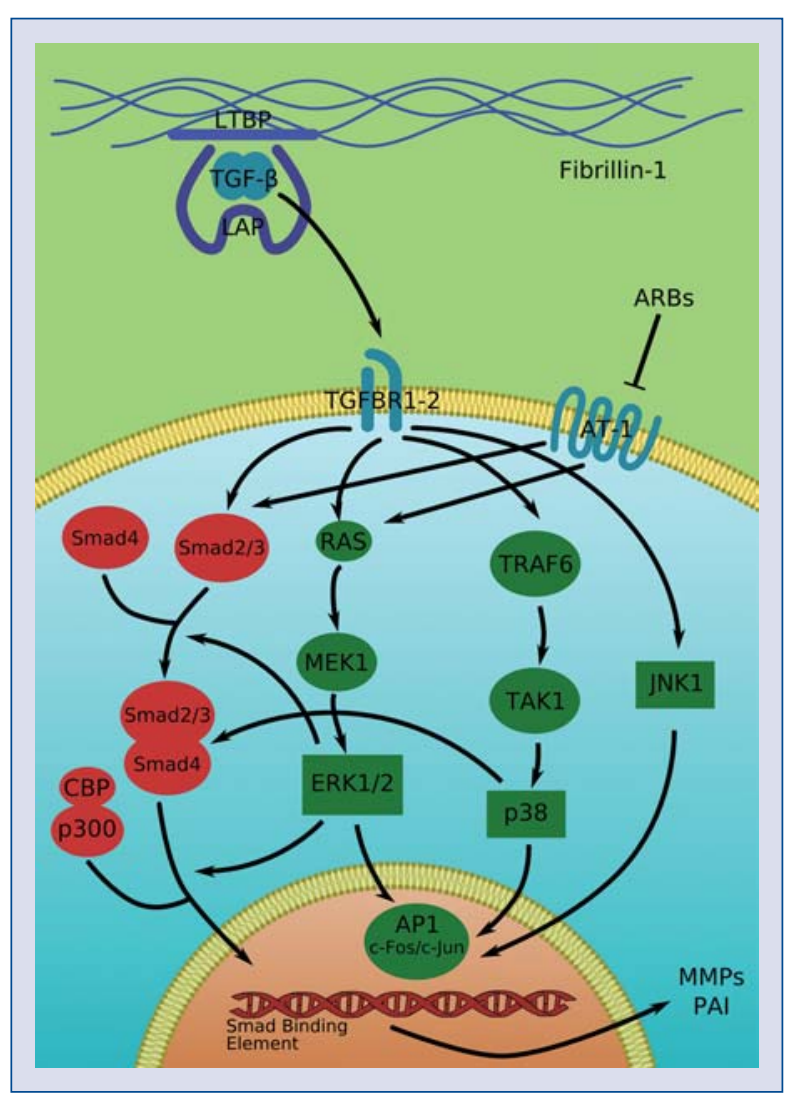

Figure 2. In this figure latent transforming growth factor-beta (TGF- $\beta$ ) activation, canonical and non-canonical TGF- $\beta$ signalling are depicted. In the extracellular matrix TGF- $\beta$ which is secreted as a small latent complex (SLC) - containing latency associated protein (LAP) and a TGF- $\beta$ dimer - binds to the latent TGF- $\beta$ binding protein (LTPB) forming large latent complex (LLC). As illustrated in the figure LLC adheres to microfibrils built from fibrillin-1 proteins. In the intracellular space Smad mediated canonical signalling (red) and non-canonical (green) p38, extracellular signal-regulated kinase (ERK1/2), and Jun $\mathrm{N}$-terminal associated kinase (JNK1) mediated pathways are shown. Genes upregulated by TGF- $\beta$ signalling (MMPs matrix metalloproteinases; PAI — plasminogen activator inhibitor) and target molecules of angiotensin receptor blockers (ARBs) through the AT-1 receptor of angiotensin II are also illustrated in the picture; TGFBR1-2 - TGF- $\beta$ binding receptor 1-2; CBP/P300 - CREB-binding protein; RAS - rat sarcoma; TAK1 - TGF- $\beta$-activated kinase 1; MEK1 - mitogen activated protein kinase 1

H3K9/14 acetylation and H3K4 methylation resulting in alteration of DNS histon proteins, finally leading to enhanced Smad2 expression [27].

$\mathrm{ERKl} / 2$ protein takes part in the regulation of Smad2-Smad4 complex, and may represent an important therapeutic target [29]. TGF- $\beta$ activation induces the phosphorylation cascade in Jun
N-terminal associated Kinase (JNK) p38/MAPK pathways as well. JNK activates c-JUN and c-FOS transcriptional factors in the cell nucleus [29]. Based on mice model experiments, JNK inhibition might be a therapeutic target, since blocking this pathway may reduce MMPs and mRNS, which play a role in Marfan pathology [29]. Erk1/2 inhibition is given emphasis in the publication, which partly explains losartan's mechanism of action [29]. Besides, inhibiting the signalling pathway of p38-MAPK also reduces MMP level, while blocking ERK 1/2 pathway enhanced the level of membrane associated MMP inhibitors (Fig. 2) [30]. Because of conflicting data on the canonical and non-canonical pathways, it is not clear which is more important in the development of the manifestations of MFS.

\section{The TGF- $\beta$ pathway overactivity}

High concentration of active TGF- $\beta$ predominates in the aforementioned mechanisms and leads to the different features of MFS. Thus, more collagen reduces the compliance of the aortic wall, which loses structural integrity and becomes dilated and aneurysmal. High interstitial concentration of TGF- $\beta$ is also responsible for reduced muscle mass, characteristic to Marfanoid habitus as TGF- $\beta$ hinders mitosis and differentiation of satellite cells which are important in the development of muscle fibres [31]. Moreover, a high TGF- $\beta$ level inhibits the fusion of satellite cells [31] and the downstream signalling pathways of endogenous bone morphogenetic protein 2 (BMP-2) in human stem cells, which is indispensable for bone and cartilage development [32]. Because of this interaction between BMP- 2 and TGF- $\beta$, the high availability of the latter molecule may be responsible for the tall stature of Marfan patients and other Marfanoid features [32].

TGF- $\beta$ upregulates the expression of elastase and many matrix-metalloproteases [33]. While an increased level of elastase enhances elastin degradation, MMPs seem to be responsible for the disintegration of elastic fibres [33]. Therefore overproduction of these proteases reduces connective tissue elasticity, and leads to weakness of the aortic wall. Connection of TGF- $\beta$ levels and MMP expression has been studied in marfan mice model [33]. TGF- $\beta$ increased $m$ RNS expression of MMP-2, MMP-9 in mice [33]. Furthermore, in the MMP-12-deficient mouse model, TGF- $\beta$-associated aortic aneurysm does not develop [34], indicating that MMP inhibition may prevent aortic pathology in MFS. Recently, MMPs have been studied in Marfan patients. Ikonomidis et al. [35] compared 
MMP and TIMP levels of 9 patients with aortic aneurysm with those of 18 non-Marfan patients with aortic aneurysm. In Marfan patients MMP-12 level was high, while TIMP-3 level was low. In the non-Marfan group, significantly lower level of MMP-1, MMP-3, MMP-8, MMP-9 and MMP-12 were found [35], suggesting a major role of MMPs in the connective tissue destruction in the aortic wall [35].

\section{Modalities of pharmacological treatment in Marfan syndrome}

Understanding the basic elements of the syndrome paved the way to various therapeutic developments with a view to pharmacological manipulations to reduce the deleterious effects of TGF- $\beta$. The first compound in such therapy was losartan, an angiotensin II receptor blocking agent (ARB) with antihypertensive effect [36]. Losartan reduces blood pressure by inhibiting the vasoconstriction produced when angiotensin II binds to its receptor, but in MFS a more important effect is to reduce TGF- $\beta$ activity and remodelling [37]. Thus, inhibition of angiotensin receptor activity is a credible therapeutic measure. Losartan administration has shown promising results in modifying the development of characteristic Marfan features in the mouse model [36]. This led to clinical trials in which a significant reduction of the aortic diameter was observed over a 1-4 year interval with losartan and irbesartan [38, 39]. Based on these findings, a multicenter study was set up in the Netherland with the involvement of 330 Marfan patients [40]. Half were given losartan. Reduction of aortic diameter as measured by MRI is the primary endpoint, and Marfan-related death, aortic dissection, surgery, aortic stiffness and left ventricular dysfunction are secondary endpoints [40]. The results of this ongoing trial will provide valuable information about the efficacy of losartan treatment, and a positive result may fundamentally modify the standard treatment of Marfan patients and their prognosis [40].

The mechanism of action for losartan is still hypothetical. Xiong et al postulated in 2012 that this mechanism may combine the inhibition of the ERK1/2 pathway and reduction of phosphorylated Smad2 levels [41] to inhibit aneurysm formation [41]. The publication also touches on the therapeutic effect of doxycycline in reducing MMP-2 level [41]. Among others, this type of metalloproteases seems to play a role in aortic dilatation and annuloaortic ectasia.
In the MMP-2-deficient mouse model designed for inhibition the activation of the TGF- $\beta$ pathway and $\mathrm{ERKl} / 2$, Smad2 phosphorylation resulted in prolongation of life [42]. This means that doxycycline therapy may reduce MMP-2 level responsible for aneurysm formation by inhibiting the noncanonical pathway [42]. Doxycycline treatment in Marfan mice caused a significant reduction in MMP-2 and MMP-9 levels and a reduction in aortic aneurysm progression and instances of aortic disruption [42].

Chung et al. [43] compared the use of the atenolol (a frontline agent in the management of aortic aneurysm) and doxycycline, a recently recognized nonspecific, intracellular MMP inhibitor. Long-term follow up showed that doxycycline is more effective in secondary prevention of aneurysm formation [43]. Single and combined administration of losartan and doxycyline in Marfan mice [44] showed a synergistic effect in the combined treatment group. Reduction of TGF- $\beta$ and MMP-2 levels prevented aneurysm formation and improved elastic fibre organization [44]. Based upon these findings, combined administration can be more effective in secondary prevention. The angiotensin converting enzyme inhibitor perindopril inhibits ECM remodeling [45]. In a randomised study of 17 Marfan patients published in 2010, ten patients received perindopril and seven placebo. All had $\beta$-blockers [45]. The perindopril group experienced a reduction of TGF- $\beta$, MMP-2 and MMP-3 levels [45]. Most recently, pravastatin was reported effective in inhibiting intensified protein synthesis in the smooth muscle cells of the aortic wall, and may be as effective as losartan in reducing aortic dilatation (Table 1) [46].

\section{Conclusions}

The study of the molecular pathogenesis of MFS may open new avenues in pharmocological therapy, which has the potential of delaying or avoiding high-risk and complex aortic surgery in these young and often asymptomatic patients. Further examination of the molecular mechanism of aortic dissection may identify reliable predictors to enable screening of these patients and optimal timing of preventive surgical intervention.

Conflict of interest: none declared

\section{References}

1. Dietz HC. Marfan syndrome. In: Pagon RA ed. GeneReviews. University of Washington, Seattle 2011: Bookshelf ID: NBK1335. 
Table 1. Conservative treatment of Marfan syndrome.

\begin{tabular}{|c|c|c|c|}
\hline $\begin{array}{l}\text { Active } \\
\text { component }\end{array}$ & Target points & Biochemical effect & Effects in Marfan syndrome \\
\hline Losartan & $\begin{array}{l}\text { Angiotensin } \\
\text { receptor blocker }\end{array}$ & $\begin{array}{l}\text { Reduction of TGF- } \beta \text { activity } \\
\text { Enhance the level of MMP inhibitors }\end{array}$ & $\begin{array}{l}\text { Prevention of progressive dilation } \\
\text { and dissection of the aorta }\end{array}$ \\
\hline Doxycyclin & MMP-2 & $\begin{array}{l}\text { MMP-2 levels are reduced, non- } \\
\text {-canonical pathway inhibition }\end{array}$ & Inhibition of aneurysm progression \\
\hline Perindopril & $\begin{array}{l}\text { Long-acting ACE } \\
\text { inhibitor }\end{array}$ & $\begin{array}{l}\text { Decrease of MMP- } 2 / 3 \text { and } \\
\text { TGF- } \beta \text { levels }\end{array}$ & $\begin{array}{l}\text { Reducing aortic root diameters and } \\
\text { the aortic stiffness }\end{array}$ \\
\hline Pravastatin & $\begin{array}{l}\text { Aortic smooth } \\
\text { muscle cells }\end{array}$ & $\begin{array}{l}\text { Excessive protein synthesis } \\
\text { inhibition }\end{array}$ & Reducing aortic root dilatation \\
\hline Atenolol & $\begin{array}{l}\text { Beta-receptor } \\
\text { blocker }\end{array}$ & Inhibition of sympathetic system & $\begin{array}{l}\text { Lowering blood pressure } \rightarrow \text { aneurysm } \\
\text { prevention }\end{array}$ \\
\hline
\end{tabular}

MMP - matrix-metalloprotease; TGF- $\beta$ - transforming growth factor-beta

2. PN Robinson, E Arteaga, $\mathrm{C}$ Baldock et al. The molecular genetics of Marfan syndrome and related disorders. J Med Genet, 2006; 43: 769-787.

3. Godfrey M, Menashe V, Weleber RG et al. Cosegregation of elastin-associated microfibrillar abnormalities with the Marfan phenotype in families. Am J Hum Genet, 1990; 46: 652-660.

4. Gao LG, Zhang L, Song L et al. Identification of a novel lethal fibrillin-1 gene mutation in a Chinese Marfan family and correlation of 3' fibrillin-1 gene mutations with phenotype. Chin Med J, 2010; 123: 2874-288.

5. Zadeh N, Bernstein JA, Niemi AK et al. Ectopia lentis as the presenting and primary feature in Marfan syndrome. Am J Med Genet A, 2011; 155A: 2661-2668.

6. Judge DP, Dietz HC. Marfan's syndrome. Lancet, 2005; 366 : 1965-1976.

7. Mariko B, Ghandour Z, Raveaud S et al. Microfibrils and fibrillin-1 induce integrin-mediated signaling, proliferation and migration in human endothelial cells. Am J Physiol Cell Physiol, 2010; 299: C987.

8. Hubmacher D, Apte SS. Genetic and functional linkage between ADAMTS superfamily proteins and fibrillin-1: A novel mechanism influencing microfibril assembly and function. Cell Moll Life Sci, 2011; 68: 3137-3148.

9. Sengle G, Tsutsui K, Keene DR et al. Microenvironmental regulation by fibrillin-1. PLoS Genet, 2012; 8: e1002425.

10. Ahram D, Sato TS, Kohilan A et al. A homozygous mutation in ADAMTSL4 causes autosomal-recessive isolated ectopia lentis. Am J Hum Genet, 2009; 84: 274-278.

11. Kutz WE, Wang LW, Hannah L et al. ADAMTS10 protein interacts with fibrillin-1 and promotes its deposition in extracellular matrix of cultured fibroblasts. J Biol Chem, 2011; 286: 17156$-17167$.

12. Ko T, Ri-ichiroh M, Tomiko $\mathrm{Y}$ et al. ADAMTSL-6 is a novel extracellular matrix protein that binds to fibrillin-1 and promotes fibrillin-1 fibril formation. J Biol Chem, 2010; 285: 4870-4882.

13. Saito M, Kurokawa M, Oda M et al. ADAMTSL6 $\beta$ protein rescues fibrillin-1 microfibril disorder in a Marfan syndrome mouse model through the promotion of fibrillin-1 assembly. J Biol Chem, 2011; 286: 38602-38613.

14. Chaudhry SS, Cain SA, Morgan A, Dallas SL, Shuttleworth CA, Kielty CM. Fibrillin-1 regulates the bioavailability of TGFbeta1. J Cell Biol, 2007; 176: 355-367.
15. Huang F, Chen YG. Regulation of TGF- $\beta$ receptor activity. Cell Biosci, 2012; 2: 9.

16. Dietz HC. Marfan syndrome: From molecules to medicines. Am J Hum Genet, 2007; 81: 662-667.

17. Lucarini L, Evangelisti L Attanasio M et al. May TGFBR1 act also as low penetrance allele in Marfan syndrome? Int J Cardiol, 2009; 1: 281-284.

18. Singh KK, Schmidtke J, Keyser B, Arslan-Kirchner M. TGFBR3 variation is not a common cause of Marfan-like syndrome and Loeys-Dietz-like syndrome. J Negat Results Biomed, 2012; 11: 9.

19. Attias D, Stheneur C, Roy C et al. Comparison of clinical presentations and outcomes between patients with TGFBR2 and FBN1 mutations in Marfan syndrome and related disorders. Circulation, 2009; 120: 2541-2549.

20. Lyons RM, Keski-Oja, J, Moses HL. Proteolytic activation of latent transforming growth factor-beta from fibroblast-conditioned medium. J Cell Biol, 1988; 106: 1659-1665.

21. Barcellos-Hoff MH, Dix TA. Redox-mediated activation of latent transforming growth factor-beta 1. Mol Endocrinol, 1996; 10: 1077-1083.

22. Schultz-Cherry S, Murphy-Ullrich JE. Thrombospondin causes activation of latent transforming growth factor- beta secreted by endothelial cells by a novel mechanism. J Cell Biol, 1993; 122: 923-932.

23. Wipff PJ, Hinz B. Integrins and the activation of latent transforming growth factor [beta]1: An intimate relationship. Eur J Cell Biol, 2008; 87: 601-615.

24. Booms P, Pregla R, Ney A et al. RGD-containing fibrillin-1 fragments upregulate matrix metalloproteinase expression in cell culture: a potential factor in the pathogenesis of the Marfan syndrome. Hum Genet, 2005; 116: 51-61.

25. Annes JP, Munger JS, Rifkin DB. Making sense of latent TGF activation. J Cell Sci, 2003; 116 (Part 2): 217-224.

26. Yu Q, Stamenkovic I. Cell surface-localized matrix metalloproteinase-9 proteolytically activates TGF-beta and promotes tumor invasion and angiogenesis. Genes Dev, 2000; 14: 163-176.

27. Gomez D, Coyet A, Ollivier V et al. Epigenetic control of vascular smooth muscle cells in Marfan and non-Marfan thoracic aortic aneurysms. Cardiovasc Res, 2011; 89: 446-456.

28. Mu Y, Gudey SK, Landström M. Non-Smad signaling pathways. Cell Tissue Res, 2012; 347: 11-20. 
29. Holm TM, Habashi JP, Doyle JJ et al. Noncanonical TGF $\beta$ signaling contributes to aortic aneurysm progression in Marfan syndrome mice. Science, 2011; 332: 358-361.

30. Gomes LR, Terra LF, Wailemann RA, Labriola L, Sogayar MC. TGF- $\beta 1$ modulates the homeostasis between MMPs and MMP inhibitors through p38 MAPK and ERK1/2 in highly invasive breast cancer cells. BMC Cancer, 2012; 12: 26.

31. Braga M, Bhasin S, Jasuja R, Pervin S, Singh R. Testosterone inhibits transforming growth factor- $\beta$ signaling during myogenic differentiation and proliferation of mouse satellite cells: potential role of follistatin in mediating testosterone action. Mol Cell Endocrinol, 2012; 350: 39-52.

32. Quarto N, Li S, Renda A, Longaker MT. Exogenous activation of BMP-2 signaling overcomes TGF $\beta$-mediated inhibition of osteogenesis in Marfan embryonic stem cells and Marfan patient specific induced-pluripotent stem cells. Stem Cells, 2012; 30: 2709-2719.

33. Chung AW, Au Yeung K, Sandor GG, Judge DP, Dietz HC, van Breemen C. Loss of elastic fiber integrity and reduction of vascular smooth muscle contraction resulting from the upregulated activities of matrix metalloproteinase-2 and -9 in the thoracic aortic aneurysm in Marfan syndrome. Circ Res, 2007; 101: 512-522.

34. Wang Y, Ait-Oufella H, Herbin O et al. TGF-beta activity protects against inflammatory aortic aneurysm progression and complications in angiotensin II-infused mice. J Clin Invest, 2010; 120: 422-432.

35. Ikonomidis JS, Jones JA, Barbour JR et al. Expression of matrix metalloproteinases and endogenous inhibitors within ascending aortic aneurysms of patients with Marfan syndrome. Circulation, 2006; 114 (1 suppl.): I365-I370.

36. Habashi JP, Judge DP, Holm TM et al. Losartan, an AT1 antagonist, prevents aortic aneurysm in a mouse model of Marfan syndrome. Science, 2006; 312: 117-121.
37. Zhou Y, Poczatek MH, Berecek KH, Murphy-Ullrich JE. Thrombospondin 1 mediates angiotensin II induction of TGF-beta activation by cardiac and renal cells under both high and low glucose conditions. Biochem Biophys Res Commun, 2006; 339: 633-641.

38. Forteza A, Evangelista A, Sánchez V et al. Study of the efficacy and safety of losartan versus atenolol for aortic dilation in patients with Marfan syndrome. Rev Esp Cardiol, 2011; 64: 492-498.

39. Brooke BS, Habashi JP, Judge DP, Patel N, Loeys B, Dietz HC $3^{\text {rd }}$. Angiotensin II blockade and aortic-root dilation in Marfan's syndrome. N Engl J Med, 2008; 358: 2787-2795.

40. Radonic T, de Witte P, Baars MJ et al. Losartan therapy in adults with Marfan syndrome: study protocol of the multi-center randomized controlled COMPARE trial. Trials, 2010; 11: 3.

41. Xiong W, Meisinger T, Knispel R, Worth JM, Baxter BT. MMP-2 regulates Erk1/2 phosphorylation and aortic dilatation in Marfan syndrome. Circ Res, 2012; 110: e92-e101.

42. Xiong W, Knispel RA, Dietz HC, Ramirez F, Baxter BT. Doxycycline delays aneurysm rupture in a mouse model of Marfan syndrome. J Vasc Surg, 2008; 47: 166-172.

43. Chung AW, Yang HH, Radomski MW, van Breemen C. Long-term doxycycline is more effective than atenolol to prevent thoracic aortic aneurysm in marfan syndrome through the inhibition of matrix metalloproteinase-2 and -9. Circ Res, 2008; 102: e73-e85.

44. Yang HH, Kim JM, Chum E, van Breemen C, Chung AW. Effectiveness of combination of losartan potassium and doxycycline versus single-drug treatments in the secondary prevention of thoracic aortic aneurysm in Marfan syndrome. J Thorac Cardiovasc Surg, 2010; 140: 305-312.

45. Ahimastos AA, Aggarwal A, Savarirayan R, Dart AM, Kingwell BA. A role for plasma transforming growth factor-beta and matrix metalloproteinases in aortic aneurysm surveillance in Marfan syndrome. Atherosclerosis, 2010; 209: 211-214.

46. McLoughlin D, McGuinness J, Byrne J et al. Pravastatin reduces Marfan aortic dilation. Circulation, 2011; 124 (11 suppl.): S168-S173. 